\title{
A Focus on the Reminiscence Bump to Personalize Music Playlists for Dementia
}

\author{
Chirag B Rao (D) \\ John C Peatfield (1D ${ }^{2}$ \\ Keith PWJ McAdam (1D ${ }^{3}$ \\ Andrew J Nunn (D) ${ }^{4}$ \\ Dimana P Georgieva $\mathbb{1 D}^{5}$ \\ 'UCL Medical School, University College \\ London, London, UK; ${ }^{2}$ The Department \\ of English Language and Literature, \\ University College London, London, UK; \\ ${ }^{3}$ London School of Hygiene and Tropical \\ Medicine, London, UK; ${ }^{4}$ Medical \\ Research Council Clinical Trials Unit at \\ UCL, Institute of Clinical Trials \& \\ Methodology, London, UK; ${ }^{5}$ Music for my \\ Mind, Harpenden, UK
}

Correspondence: Chirag B Rao UCL Medical School, University College London, London, WCIE 6DE, UK Tel +447850674672

Email chiragbrao@gmail.com
Purpose: Music and memory are inextricably linked, and the recollection of music varies according to age. In order to create personalized music playlists tailored for people living with dementia, this study aimed to determine the age at which healthy individuals could best recall music that was popular at the time.

Methods: A survey was designed asking participants to identify the number of songs they recalled from a random selection of 10 from the 100 most popular songs from each year, presented in random order of years, from 1945 to 2015 . Of the 311 individuals born between 1929 and 2002, who responded to the survey, 157 met the inclusion criteria.

Results: The median peak of recollection was between the ages of 13 and 19 across all agecohorts, with participants recalling a maximum median number of 6-8 songs in all of the age-cohorts. There was no evidence of a difference in the peak age of recollection between those who recognized seven or more songs in at least 1 year and those who recognized fewer than seven songs in all years.

Conclusion: The peak of recollection of popular music occurs in the teenage years, regardless of era of birth. Music from this "reminiscence bump" provides a rich source of retained music that should be tapped when creating playlists of meaningful music for people living with dementia.

Keywords: music therapy, neurocognitive disorders, memory, quality of life

\section{Plain Language Summary}

Music plays an important role in memory, with studies finding that musical memory can be retained through an individual's lifetime. This study aimed to find the ages from which popular music was best recalled in order to be able to create music playlists that focus on music from that particular era. Listening to personally meaningful music can improve the quality of life of patients with dementia, as described in reminiscence therapy. With the prevalence of Alzheimer's Disease expected to triple by 2050, such data can also provide helpful direction for future treatment.

An online survey presented a random selection of 10 of the 100 most popular songs from each year of the music charts, between 1945 and 2015, presented in random order. Of the 311 participants born between 1929 and 2002 who were enrolled in the survey, 157 met the inclusion criteria.

The results showed that popular music was best recalled when people were aged between 13 and 19 years, regardless of their year of birth. This represents substantial evidence that an interest in popular music improves recall and implies that music from the teenage era can be used to create personalized music playlists to help people living with dementia, who may not be able to recall the names of their favorite music. It not only provides opportunities to reminisce but also helps build bridges with family, friends and caregivers. 


\section{Introduction}

Introductions to papers concerned with memory tend, in their more poetic moments, to be drawn to quotations from Marcel Proust's Remembrance of Things Past, finding Proust's journey through youth, memory and desire particularly apposite to their nostalgic, if methodical, discussions. In the present instance, a quotation from D. H. Lawrence ${ }^{1}$ might be more appropriate:

Softly, in the dusk, a woman is singing to me;

Taking me back down the vista of years, till I see

A child sitting under the piano, in the boom of the tingling strings

And pressing the small, poised feet of a mother who smiles as she sings.

(Piano, 1918)

The relationship between music and emotion has been well documented. Music has been found to induce or at least represent emotion, ${ }^{2}$ and it has been hypothesized that this yearning for an emotional response, or reflection of a preexisting emotional state, is the primary reason given for listening to music at all. ${ }^{3}$ Others have found that musical experience dates to the very earliest of memories and, as singing induces emotional well-being, that these early memories were universally positive. ${ }^{4}$

The relationship between memory and emotion has also been clearly described. It is commonly supposed, with evidence from studies showing that memories are most vivid when connected to moments of heightened emotional range. ${ }^{5}$ Culturally normative events usually filled with emotion, such as births, marriages and deaths, were found to be the best remembered of autobiographical memories; ${ }^{6}$ it seems the more emotional the occasion, the better it is encoded in memory.

Often, in studies which seek to confirm this propensity for the increased vividness of emotional memory, music, with its ability to reflect and induce, is used as the stimulus. For example, Schulkind ${ }^{7}$ played 20 second excerpts of popular songs to two groups of listeners, one with an age range of $18-21$, the other $65-70$, asking participants to measure their emotional response to each song and take a short quiz (artist, title, year and a few lyrics) to judge their memory. For both groups, there was a significant correlation between reported emotional response and the detail participants could recall about the song. This was especially true for the older adults, who were found not only to have greater emotional responses to the songs of their youth but also a far greater ability to remember them in detail. Yet there are limits to this association of music and memory, with Schulkind warning against anecdotes of a sudden return of a complete memory of lyrics in older patients, stating "[s]inging the words to a popular song, even one that is well liked, is not nearly as important as being able to find one's way home".

Nevertheless, musical memory has been found to be retained throughout an individual's lifetime by studies, where older patients were able to recall details of songs first performed, and indeed heard, 60 years beforehand. They also found these musical memories were almost all connected in some way to autobiographical memory, with very few able to recall music as clearly from before their birth. Indeed, the last time participants reportedly heard a song often correlated with when it was popularly released. ${ }^{8}$

This leads to the other finding common to these publications: to a greater or lesser extent autobiographical memories, especially those connected to music, have a far greater vividness for those formed (or rather, music heard) in early adolescence. Whenever individuals were asked to recall especially vivid memories, these disproportionately came from early adolescence, ${ }^{9-11}$ Holbrook and Schindler connected these early memories to music, finding individuals have far more emotional affection for songs first heard in early adolescence. ${ }^{12}$ Considering this relationship between the emotions of youth and memory ability, it is no surprise then that it was also found that an individual's mean age when their favorite film was released was $28,{ }^{13}$ and that each generation's political identity is shaped by the events that occurred in its early adulthood, which are in turn better remembered in later life. ${ }^{14}$ Media absorbed in early adolescence clearly leaves the greatest impression on our lives, both in character and in memory.

This phenomenon, the propensity for the quality and quantity of autobiographical memories to be clustered into the years of adolescence and young adulthood, is often dubbed the "reminiscence bump". Papers vary in their exact definition of the peak of this bump, but most, put it between 15 and 25 years of age. ${ }^{15-18}$ Rubin ${ }^{10}$ discusses the four primary explanations for this phenomenon: the cognitive explanation (that the constant rapid changes of adolescence provide that novelty of experience which is most durably encoded in memory); the neural explanation (that 
cognitive ability is far more effective when younger); the theory of identity formation (that the events of youth gain a far greater significance in lasting personalities); and finally the idea of genetic fitness (that as a product of the enhanced capabilities enjoyed at the time of greatest "fitness", individuals also enjoy a greater ability to remember). Fortunately given these findings, Rubin and Berntsen ${ }^{19}$ found that memories from the reminiscence bump tend to be positive rather than negative.

As can be seen, the relationship between music, memory and emotion is well documented, but many of these studies were carried out over 30 years ago. Although this does not invalidate their findings, many of their older participants (say, 80-year-olds in 1990) would have had their early musical experiences before the boom of popular radio. The popular music station, Radio Caroline, for example, was founded in 1964, the same year the BBC commissioned Top of the Pops, a weekly television program which played the top songs from the last seven days. Only in recent years will the majority of older participants have experienced music in much the same format as is available today: through $\mathrm{TV}$, radio and the physical objects of discs, cassettes and then CDs, although online streaming services such as YouTube and Spotify have dominated music listening over the last 10 or so years. This helps to level the field of accessibility and exposure, as has the universality of the 3-minute pop song (as opposed to longer classical or jazz arrangements) allowed for much the same type of listening over the last 50 years.

The well-established link between music and emotion therefore provides an opportunity to move into clinical practice. Currently, over 50 million people worldwide suffer from dementia, with Alzheimer's disease (AD) being the most common variant. With an increasing ageing population, the worldwide prevalence is expected to triple by $2050 .{ }^{20} \mathrm{AD}$ is a progressive neurodegenerative disorder that causes memory loss, cognitive decline and the inability to complete even simple tasks over time. There are many theories for the pathophysiology of $\mathrm{AD}$, with plaques and tangles forming in the matter of the brain accompanied by the destruction of neurons. It is thought to begin in the hippocampus, affecting learning and memory. ${ }^{21}$ This can have various neuropsychiatric effects on patients, through loss of independence and emotional variability. ${ }^{22}$ Depression, psychosis, apathy, anxiety and agitation are core symptoms of $\mathrm{AD}^{22}$ This is increasingly marked at nighttime, with the "sundowning" effect. A range of psychological and behavioral disturbances are recognized by those who provide care, often triggered by daily caring tasks such as toileting and bathing, dressing and getting ready for bed.

As stated last year in a commission by the Lancet, "wellbeing is the goal of much of dementia care. ${ }^{23}$ " Receptive Music Therapy (RMT) provides an exciting opportunity to ameliorate this. Various studies have highlighted its effectiveness and all find the intrinsic link between the improvement in symptoms and memory. Damage to the hippocampus in $\mathrm{AD}$ affects declarative memory more than emotional recall and the amygdala sparks emotional memory through pathways independent of the hippocampus; thus, repeated sessions can help preserve emotional memory. Furthermore, regions such as the anterior cingulate cortex and the ventral presupplementary motor area that may be preferentially involved in the processing of long-known as compared to recently known or unknown musical stimuli show minimal structural atrophy in dementia. ${ }^{24}$ Music has been found to stimulate regions including the anterior cingulate cortex by eliciting a spectrum of emotions. ${ }^{25-27}$ Ngo \& HolroydLeduc $^{28}$ recommend music should be a commonly used intervention for people living with dementia.

RMT has been found to improve happiness and decrease sadness in subjects, whilst also decreasing cortisol and increasing melatonin concentrations, reducing stress and improving quality of sleep. ${ }^{29,30}$ Noting that RMT can help to reduce psychological and behavioral symptoms, improving the quality of life of participants, Cunningham et $\mathrm{al}^{38}$ suggested that by associating music with a task, the participant with $\mathrm{AD}$ would complete the task more successfully, thus improving quality of life. In the context of personalized music, Costa et $\mathrm{al}^{31}$ found that listening to "preferred music" decreased depression scores in a sample of care home residents. When extended to a population of participants with Alzheimer's Disease, Murphy et $\mathrm{al}^{32}$ provided specific personalized music therapy to care home residents and found improved goaloriented activity and emotional expression during sessions. This study had a sample size of 75 residents and heterogeneity in the frequency of delivery, but showed positive findings including (verbal) reminiscing during sessions. One point of discussion was the amount of effort it took to titrate playlists carefully for each resident. By identifying a specific era for the reminiscence bump, personalized music therapy could be more practicable, making treatment more accessible to a larger sample, with a less intensive approach. Other studies ${ }^{33}$ have used instruments to 
cultivate known music such as Gerdner's “Assessment of Personal Music Preference",34,35 and even this intensive method of tailoring music could be simplified.

The present study aimed to ascertain the age at which healthy individuals can best recall the popular music of that particular era. Qualitative data and descriptive reports abound on the impact of music on emotional responses; however, more quantitative data is needed. By defining the age range in which popular music is most likely to be remembered and recalled makes it logical to focus on this "reminiscence bump" era when selecting personally meaningful music for people living with dementia.

\section{Materials and Methods}

Music for my Mind (MFMM) is a charity that seeks to build the evidence base for the use of music for people living with dementia, their care-providers and loved-ones. The Music for my Mind Reminiscence Bump Study was designed to determine the age at which popular music is best recalled in healthy volunteers. Individuals born between 1929 and 2002 were invited to complete the survey, as this is the age range most at risk of developing dementia over the next 50 years.

\section{Survey Population}

The on-line survey was sent to participants through the MFMM newsletter and social media platforms. Participants were encouraged to advertise the survey through word of mouth. The survey required respondents to give their year of birth and if they had spent their youth in the UK. The instructions to participants were that recognition of a song was determined by the ability to hum the chorus or first line of a song without prompting. On-line informed consent was given by all participants with the understanding that data would be used for research. No personal data were collected except age and whether they grew up in UK. Participants clearly had to be competent and confident enough to manage their computers or phones to complete the on-line survey. The data were anonymous. Within our population $(n=157) 14$ people were born outside the UK. There was little evidence to suggest any difference in responses from those in the UK, so they were not analyzed separately.

As shown in Table 1, a total of 311 persons participated in the survey; 145 of those invited were excluded initially, for completing the survey incorrectly. This included leaving considerable parts of the survey blank $(n=124)$, answering with a written description of only one song per year in the years where songs were recalled $(n=10)$, answering with
Table I Age Distribution of Study Participants

\begin{tabular}{|l|c|c|}
\hline Year of Birth & Invited Participants & Analyzed Population \\
\hline Pre 1940 & 10 & 0 \\
$1940-1949$ & 62 & 31 \\
$1950-1959$ & 82 & 49 \\
$1960-1969$ & 55 & 33 \\
$1970-1979$ & 54 & 31 \\
$1980-1989$ & 29 & 13 \\
$1990-1999$ & 12 & 0 \\
$2000-2009$ & 2 & 0 \\
Not known & 5 & 0 \\
\hline Total & 311 & 157 \\
\hline
\end{tabular}

only a "yes" or "no" $(\mathrm{n}=2)$, answering with a number greater than $10(\mathrm{n}=4)$ and not providing a year of birth $(n=5)$. Subsequently, those born before $1940(n=4)$ or after $1989(n=5)$ were excluded on account of small numbers, with total exclusions being 154, leaving 157 for analysis.

Questions were presented to participants using SurveyMonkey (SVMK Inc, USA) and designed to be simple to complete. They were shown the names of 10 of the most popular songs of each year from 1945 to 2015 , presented in random year order and were asked to identify how many they recognized (Box 1), on the basis of whether they could hum the tune or the chorus. The ten songs were randomly selected, using an online randomizer, ${ }^{36}$ from a book ${ }^{37}$ that charted the top 100 songs from each year from 1915 to 2015 derived from several chart archives. The survey was completed in the participants' own time, but it was strongly recommended

Box I Example question from the on-line survey, showing 10 randomly selected songs from 1984.

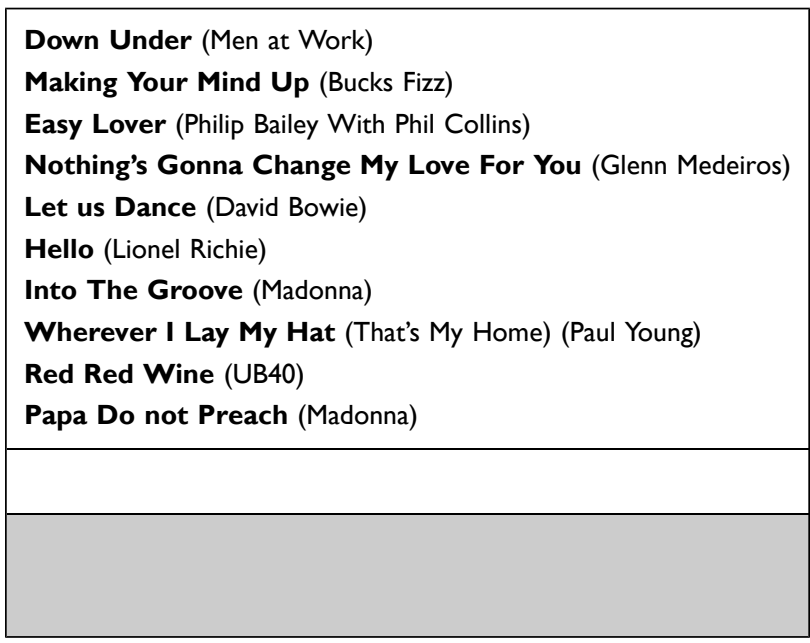

Notes: The Answer Was Typed into the Gray Box. Data from Grech. ${ }^{37}$ 
that they should limit themselves to around 30 minutes to complete the survey, with about 10 seconds per question and they were asked to refrain from looking up or playing any of the songs.

Data were analyzed using Excel (Microsoft, USA), Stata (StataCorp, USA) version 16.1 and Prism (GraphPad, USA). The data were not normally distributed and so non-parametric statistical methods were used.

\section{Results}

As shown in Figure 1, the peak of music retention is between the ages of 13 and 19, during which time participants recalled a maximum median of 6-6.5 songs each year.

As the music selections presented were released from 1945 to 2015, younger participants were presented with music tracks that were released prior to their birth. This accounts for the negative values on the horizontal axis, reflecting recognition of music that was often released many years before they were born.

A sub-analysis was conducted to assess whether the pattern observed above was modified in any way when limited to the participants who recognized a greater number of songs, arbitrarily defined as those who recognized at least seven songs in any single year.

Figure 2 confirms the findings shown in Figure 1. The 131 participants, who could recall more than seven songs in at least 1 year, clearly illustrated greatest recall of music that was popular in the teenage years, during which time they

\section{$n=157$}

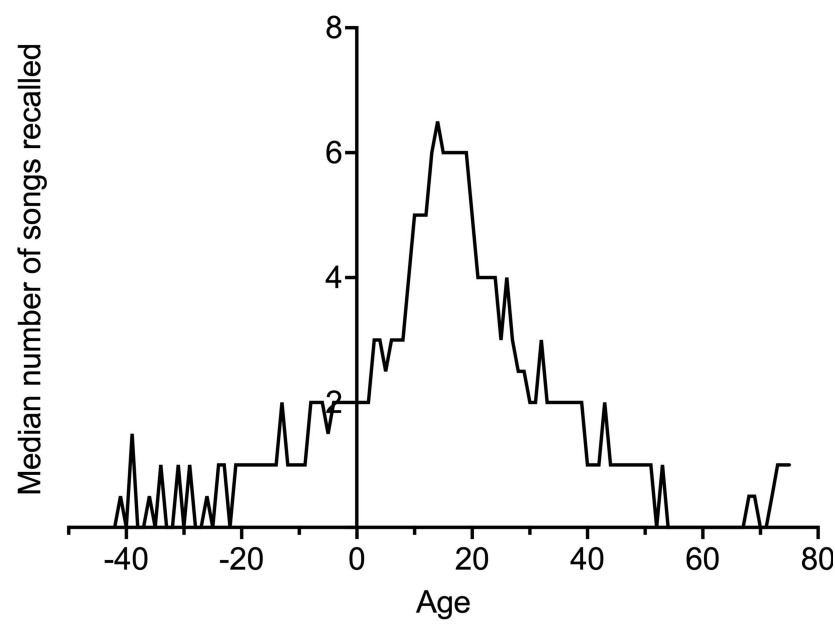

Figure I Graph showing the median number of songs recalled. The peak recollec tion of $6+$ songs occurred between the ages of 13 and 19 years old.

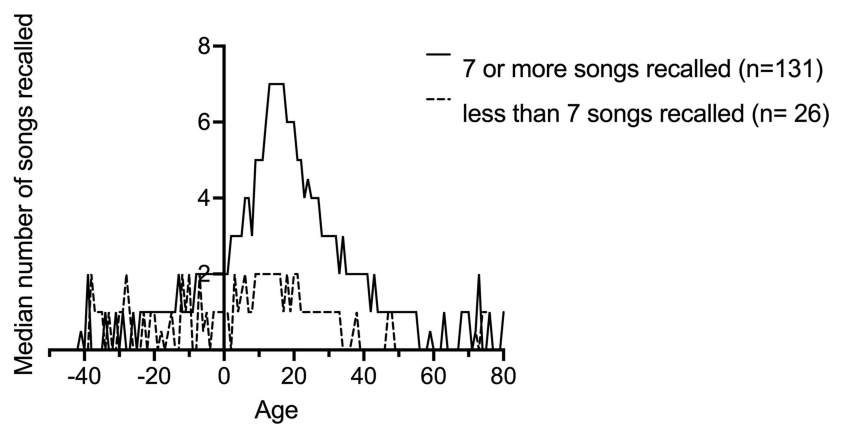

Figure 2 Graph showing the median number of songs recalled, comparing those recalling seven or more songs in any single year $(n=|3|)$ and those who identified fewer than seven songs in all years. $(n=26)$.

recognized a maximum median of seven songs per year. In those participants who were unable to recall seven songs in any 1 year $(n=26)$, there was no clear association with age. Furthermore, the maximum median number of songs recalled per year never exceeded 2. Recall of songs released before birth is similar in both groups, with a maximum median of two songs remembered from this period.

The pattern of maximum recall occurring during teenage years is consistent across all the year-of-birth cohorts. The maximum median ranged from six to eight songs recalled by each of the cohorts and the age of this peak recall ranged from 13 to 19 years in every cohort, as seen in Figure 3.

\section{Discussion}

The qualitative benefit of Receptive Music Therapy (RMT) in patients with dementia has been well described elsewhere. ${ }^{31,32,38,39}$ This project aimed to provide quantitative evidence of the age in healthy individuals when popular music was best recalled, thereby demonstrating an era for the reminiscence bump. This era could then be sampled to create personalized playlists for RMT in people living with dementia.

Our data demonstrate clearly that healthy individuals recognize popular music songs best from their teenage era, peaking between 13 and 19 years of age. As noted earlier, reminiscence and nostalgia are key to recollection of music. Remembered music is intrinsically linked to autobiographical memory, and by tapping into nostalgia and emotion, one may evoke such memories. ${ }^{10,19}$ But why does this peak occur so late in youth? Some argue that music from early childhood may be ingrained into our subconscious. However, a degree of childhood amnesia between 0 and 8 years of age ${ }^{40}$ might partly account for a relative lack of music memories in early childhood. 

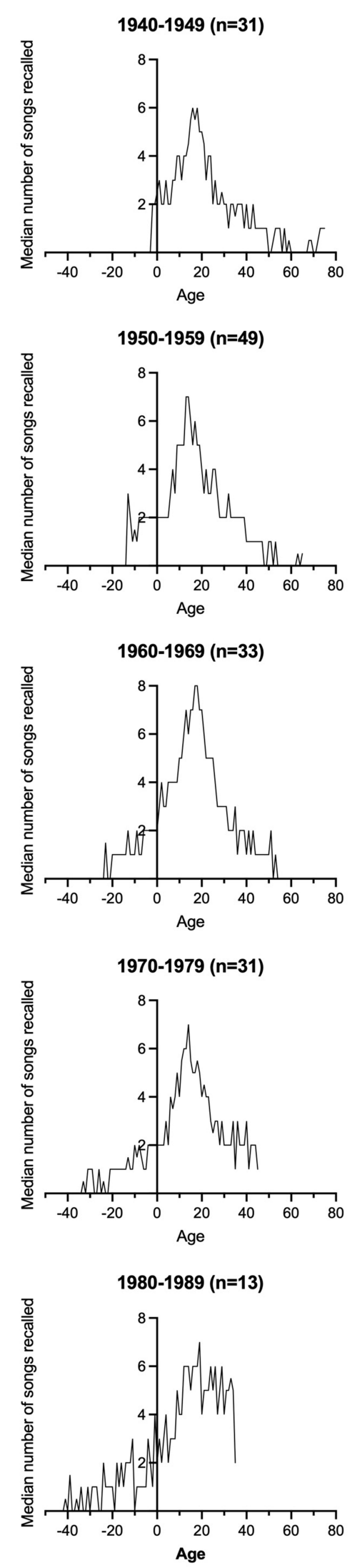

Figure 3 Graphs showing the median number of songs recalled by age, in each 10 year date-of-birth cohort. As seen, all the graphs follow a similar trend, with the pattern of maximum recall occurring during the teenage years.
Furthermore, speculation about the songs recognized from the years prior to birth includes intergenerational influences in music between younger and older family members, such as children with their parents and grandparents.

When considering the narrative or identity account of teenage years, many important life events occur during this transitional period where social identity is formed ${ }^{41}$; children attend secondary school, relationships develop and puberty occurs. Music forms a soundtrack to this period of life, as adolescents develop into the individuals they are going to become. They form and consolidate goals, learn to critique themselves and evaluate progress. Songs are easily identified with fluctuating teenage emotions, relationships and life changes. These results therefore assert that the adolescent years are even more important than those from 20 to 30 , another suggested period for the reminiscence bump. ${ }^{41}$ Events in these turbulent years are also recalled more frequently throughout life, thus etching them into memory. ${ }^{42}$ According to the cognitive model, the brain matures during the period of adolescence and early adulthood, leading to increased recall later on in life, ${ }^{41}$ again supporting the evidence in Figure 1.

The present study was designed to assess whether people born in different eras would recall popular music from different stages in their lives. The finding that the music reminiscence bump was consistent during teenage years, irrespective of the date of birth of the participant, suggests an important association of potent emotional experiences during this era and exposure to popular music. These factors all contribute to differential encoding in memory, with this period remembered more vividly than other periods of life. ${ }^{42}$

Accessibility of music to people of different ages could be predicted to be relevant. In the mid-20th century, family time often centered around the radio, from tuning in to $\mathrm{BBC}$ together, to the hugely popular appeal of listening to music on Radio Luxembourg and Radio Caroline all around the world. Those who grew up in the 1960s onwards had a greater exposure to personal audio through the advent of cassette players giving them the ability to record their own tracks from the radio. However, over time, the radio became a less popular vehicle for music. Many who grew up in the 1970s and 1980s lived through a transition period, as television became more popular and young adolescents were more interested in watching the latest music video on MTV. Although the methods of engaging with music have inevitably changed over the 
years, new vehicles for delivery of popular music have increased the accessibility to popular music that evokes powerful memories of togetherness and nostalgia, thus endorsing the relevance of reminiscence therapy.

Cultural differences, which include significant life transitional events, would be expected to provide heterogeneity in reminiscence responses to music. Further studies engaging people from different cultural backgrounds will be required to assess the impact of this cultural script on the ages of the reminiscence bump.

In Receptive Music Therapy (RMT), the patient may engage with the music by singing along or clapping, though that is not a prerequisite. Other forms of music therapy include neurologic music therapy (NMT) which uses music for neural entrainment. ${ }^{43}$ This relies on transmission of information from the auditory and motor centers of the brain, in order to improve motor symptoms in various neurological conditions. In other studies, NMT has been used to aid the psychosocial symptoms of dementia. $^{44}$ Techniques such as Musical Sensory Orientation Therapy and Musical Attention Control Therapy use elements of musicality, such as rhythm and melody to both orient the participants in time and space and to improve attentive functions. Although not always successful, such studies have assessed the question as to how important knowing the music actually is and whether it is the elements of the music, and not just the emotional attachment that provides the response in participants. ${ }^{44}$

The study has a number of limitations. It is not possible from this study to generalize about musical interests and evoked emotions of individual participants. In addition, no data on gender of respondents were collected. Although there was no neurocognitive assessment of participants, they were able to manage the on-line process of concentrating on and answering the survey questions, which clearly required considerable cognitive skills.

As alluded to earlier, some participants would have little or no interest in popular music. Some will have grown up listening to hymns and/or classical music, rather than popular chart music, which provides an opportunity for further consideration in the future. In our study, participants were arbitrarily designated as either "interested" in popular music, having recognised seven songs or more in at least 1 year, and those who were "less interested". As seen in Figure 2, participants who were more interested in popular music followed the pattern of the reminiscence bump in the teenage years. In those defined as less interested in popular music, there was no discernible age pattern for recollection of popular music. This highlights the importance of personalized music and provides evidence to support the creation of personalized playlists tailored to age and genre. This is particularly relevant to people living with short-term memory loss and dementia, who often cannot remember the names of their favorite songs. In order for the individual to benefit from the desired effects of music therapy, it would help if they were familiar with the music. Since an emotional attachment to music in RMT is thought to be beneficial, ${ }^{7}$ personalized playlists could be most effectively created by focusing on music that was relevant during their adolescent years.

People living with dementia, who lose short-term memory, may yet retain musical memory from their teenage era - their reminiscence bump. Indeed, ongoing pilot studies indicate that meaningful music can raise mood and help alleviate acute behavioral and psychological manifestations of dementia. Successful musical events in care homes often use popular music from times past. This study was initiated to learn more about how to select music for people living with dementia and affirms that personalized music from an individual's teenage era is a good place to start. Music for my Mind has been compiling personalized playlists for people living with dementia from the reminiscence bump years, further personalized by answers to a music preferences questionnaire. Published data suggest that music memory is relatively well preserved $^{45,46}$ and that individuals living with dementia are able to enjoy music, even in later stages of the condition, providing a strong rationale for the development of music-based interventions. Future studies will attempt to identify specific regions of the brain that are activated by music that induces positive responses.

\section{Conclusions}

This study has shown that popular music that is most readily recalled is that which was being played during an individual's teenage years, a reminiscence bump between the ages of 13 and 19. Recall of music is likely to be influenced by having an interest and emotional entwinement with this music. The findings strengthen the case for creating personalized playlists for Receptive Music Therapy for people living with dementia, which would be particularly useful in social prescribing. It is widely held that favorite music can be effective at averting or reducing some of the psychological and behavioral symptoms associated with dementia. Music for my Mind is 
supporting novel ways to create personalized playlists and to deliver music in different care settings. In people who cannot recall their favorite music because of their cognitive deficit, this study endorses the approach of focusing on music that was popular during their teenage era. This period of adolescence is clearly an influential age, with emotional and cognitive scripts taking a forefront in life as the brain matures and important experiences take place. Music provides a background for this period of life and is retained and recalled animatedly from this period, suggesting that an emotional link to the music inspires recollection.

\section{Abbreviations}

AD, Alzheimer's disease; MFMM, Music for my Mind; RMT, Receptive Music Therapy; NMT, Neurologic Music Therapy.

\section{Data Sharing Statement}

The data that support the findings of this study are available from the corresponding author, CR, upon reasonable request.

\section{Ethics Statement}

The Research Advisory Group of MFMM considered that this anonymous survey did not require formal review from a Research Ethics Committee, as participants were informed about the study on-line before volunteering to participate, they were not selected based on health status, the same survey was provided to all volunteers and no participant identifiers were retained. When a UK Research and Innovation Medical Research Questionnaire was completed, it was deemed that Research Ethics Review was not required in England. Volunteers agreed to participate in this anonymous online research study whose results would later be presented and published and they could withdraw at any time without any adverse repercussions.

\section{Clinical Implications}

- The findings strengthen the case for creating personalized playlists for Receptive Music Therapy (RMT) for people living with dementia.

- This study endorses the approach of focusing on music that was popular during the teenage era, a time which coincides with emotional and cognitive scripts accompanying important life experiences during this period of adolescence.

\section{Author Contributions}

All authors made a significant contribution to the work, in either the conception, study design, execution, acquisition of data, analysis and interpretation, or in all these areas; took part in drafting. All contributed to revising and critically reviewing the article; gave final approval of the version to be published; have agreed on the journal to which the article has been submitted; and agree to be accountable for all aspects of the work.

\section{Funding}

The costs of the study were borne by MFMM (registered charity number 1167246). Publication fees were covered by University College London.

\section{Disclosure}

The authors report no conflicts of interest in this work.

\section{References}

1. Lawrence D. Piano. In: Selected Poems. 2nd ed. London: Penguin Books Ltd; 1954:30.

2. Krumhansl CL. An exploratory study of musical emotions and psychophysiology. Can J Exp Psychol. 1997;51(4):336-352. doi:10.1037/1196-1961.51.4.336

3. Panksepp J. The emotional sources of "chills" induced by music. Music Percept. 1995;13(2):171-207. doi:10.2307/40285693

4. Krøjgaard P, Kingo OS, Berntsen D. Adults' earliest memories of songs and melodies based on a large stratified sample. Mem Stud. 2015;10(2):210-226. doi:10.1177/1750698015622057

5. Bower GH. Mood and memory. Am Psychol. 1981;36(2):129-148. doi:10.1037/0003-066X.36.2.129

6. Berntsen D, Rubin DC. Cultural life scripts structure recall from autobiographical memory. Mem Cognit. 2004;32(3):427-442. doi:10.3758/BF03195836

7. Schulkind MD, Hennis LK, Rubin DC. Music, emotion, and autobiographical memory: they're playing your song. Mem Cognit. 1999;27(6):948-955. doi:10.3758/BF03201225

8. Bartlett JC, Snelus P. Lifespan memory for popular songs. Am J Psychol. 1980;93(3):551-560. doi:10.2307/1422730

9. Fitzgerald JM. Vivid memories and the reminiscence phenomenon: the role of a self narrative. Hum Dev. 1988;31(5):261-273. doi: $10.1159 / 000275814$

10. Rubin DC, Rahhal TA, Poon LW. Things learned in early adulthood are remembered best. Mem Cognit. 1998;26(1):3-19. doi:10.3758/ BF03211366

11. Benson KA, Jarvi SD, Arai Y, Thielbar PRS, Frye KJ, McDonald BLG. Socio-historical context and autobiographical memories: variations in the reminiscence phenomenon. In: Conway MA, Rubin DC, Spinnler H, Wagenaar WA, editors. Theoretical Perspectives on Autobiographical Memory. Springer Netherlands: Dordrecht; 1992:313-322. doi:10.1007/978-94-015-7967-4_18

12. Holbrook MB, Schindler RM. Some exploratory findings on the development of musical tastes. J Consum Res. 1989;16(1):119-124. doi: $10.1086 / 209200$

13. Sehulster JR. In my era: evidence for the perception of a special period of the past. Memory. 1996;4(2):145-158. doi:10.1080/ 096582196389013 
14. Conway MA. The inventory of experience: memory and identity. In: Collective Memory of Political Events: Social Psychological Perspectives. Routledge. 1997:21-45.

15. Rathbone CJ, O'Connor AR, Moulin CJA. The tracks of my years: personal significance contributes to the reminiscence bump. Mem Cognit. 2017;45(1):137-150. doi:10.3758/s13421016-0647-2

16. Cappeliez P. An explanation of the reminiscence bump in the dreams of older adults in terms of life goals and identity. Self Identity. 2008;7 (1):25-33. doi:10.1080/15298860600934281

17. Davison IM, Feeney A. Regret as autobiographical memory. Cogn Psychol. 2008;57(4):385-403. doi:10.1016/j. cogpsych.2008.03.001

18. Steiner KL, Pillemer DB, Thomsen DK, Minigan AP. The reminiscence bump in older adults' life story transitions. Memory. 2014;22 (8):1002-1009. doi:10.1080/09658211.2013.863358

19. Rubin DC, Berntsen D. Life scripts help to maintain autobiographical memories of highly positive, but not highly negative, events. Mem Cognit. 2003;31(1):1-14. doi:10.3758/BF03196077

20. Jennings A, Cunnane SC, Minihane AM. Can nutrition support healthy cognitive ageing and reduce dementia risk? BMJ. 2020;369: m2269. doi:10.1136/bmj.m2269

21. Anand KS, Dhikav V. Hippocampus in health and disease: an overview. Ann Indian Acad Neurol. 2012;15(4):239-246. doi:10.41 03/0972-2327.104323

22. Li X-L, Hu N, Tan M-S, Yu J-T J-T, Tan L. Behavioral and psychological symptoms in alzheimer's disease. Rosenmann H, ed. Biomed Res Int. 2014;2014:927804. doi:10.1155/2014/927804

23. Livingston G, Huntley J, Sommerlad A, et al. Dementia prevention, intervention, and care: 2020 report of the lancet commission. Lancet. 2020;396(10248):413-446. doi:10.1016/S0140-6736(20) 30367-6

24. Baird A, Samson S. Memory for music in alzheimer's disease: unforgettable? Neuropsychol Rev. 2009;19(1):85-101. doi:10.1007/ s11065-009-9085-2

25. Mitterschiffthaler MT, Fu CHY, Dalton JA, Andrew CM, Williams SCR. A functional MRI study of happy and sad affective states induced by classical music. Hum Brain Mapp. 2007;28 (11):1150-1162. doi:10.1002/hbm.20337

26. Koelsch S. Brain correlates of music-evoked emotions. Nat Rev Neurosci. 2014;15(3):170-180. doi:10.1038/nrn3666

27. Sachs M, Habibi A, Damasio H. Chapter 8 - reflections on music, affect, and sociality. In: Christensen JF, Gomila ABT-P in BR, editor. The Arts and the Brain. Vol. 237. Elsevier; 2018:153-172. doi:10.1016/bs.pbr.2018.03.009

28. Ngo J, Holroyd-Leduc JM. Systematic review of recent dementia practice guidelines. Age Ageing. 2015;44(1):25-33. doi:10.1093/ageing/afu143

29. Kumar AM, Tims F, Cruess DG, et al. Music therapy increases serum melatonin levels in patients with alzheimer's disease. Altern Ther Health Med. 1999;5(6):49-57.

30. de la Rubia Orti JE, Pardo MP, Benllochi M, et al. Music therapy decreases sadness and increases happiness in Alzheimer patients: a Pilot Study. Neuropsychiatry. 2019;9(1):2013-2020. doi:10.4172/ neuropsychiatry. 1000546

31. Costa F, Ockelford A, Hargreaves DJ. The effect of regular listening to preferred music on pain, depression and anxiety in older care home residents. Psychol Music. 2017;46(2):174-191. doi:10.1177/0305 735617703811
32. Murphy K, Liu WW, Goltz D, et al. Implementation of personalized music listening for assisted living residents with dementia. Geriatr Nurs. 2018;39(5):560-565. doi:10.1016/j. gerinurse.2018.04.001

33. Garrido S, Dunne L, Chang E, Perz J, Stevens CJ, Haertsch M. The use of music playlists for people with dementia: a critical synthesis. J Alzheimers Dis. 2017;60(3):1129-1142. doi:10.3233/JAD-170612

34. Gerdner LA, Hartsock J, Buckwalter KC. Assessment of personal music preference (family version). In: Univ Iowa Gerontol Nurs Interv Res Cent Res Dev Dissem Core, Iowa City, Iowa. 2000. Available from: https://www.health.ny.gov/diseases/conditions/demen tia/edge/forms/edge_project_indiv_music_assessment.pdf. Accessed June 22, 2021.

35. Gerdner LA, Titler M. Series on evidence-based practice for older adults. 2007.

36. Random.org. List randomiser. Available from: Random.org. Accessed August 15, 2019.

37. Grech P. 100 Years: A Century of Song. 1sted. Glasgow: Playlist for Life; 2019. Available from: https://www.playlistforlife.org.uk/the100-years-book/. Accessed June 22, 2021.

38. Cunningham S, Brill M, Whalley JH, et al. Assessing wellbeing in people living with dementia using reminiscence music with a mobile app (Memory tracks): a Mixed Methods Cohort Study. Zollo L, ed. $J$ Healthc Eng. 2019;2019:8924273. doi:10.1155/2019/8924273

39. Soufineyestani M, Khan A, Sufineyestani M. Impacts of music intervention on dementia: a review using meta-narrative method and agenda for future research. Neurol Int. 2021;13(1):1-17. doi:10.33 90/neurolint13010001

40. Bauer PJ, Larkina M. The onset of childhood amnesia in childhood: a prospective investigation of the course and determinants of forgetting of early-life events. Memory. 2014;22(8):907-924. doi:10.1080/ 09658211.2013 .854806

41. Munawar K, Kuhn SK, Haque S, Semkovska M. Understanding the reminiscence bump: a systematic review. PLoS One. 2018;13(12): e0208595. doi:10.1371/journal.pone.0208595

42. Janssen SMJ, Chessa AG, Murre JMJ. Temporal distribution of favourite books, movies, and records: differential encoding and re-sampling. Memory. 2007;15(7):755-767. doi:10.1080/09658210701539646

43. Thaut MH, McIntosh GC, Hoemberg V. Neurobiological foundations of neurologic music therapy: rhythmic entrainment and the motor system. Front Psychol. 2015;5:1185. doi:10.3389/fpsyg.2014.01185

44. Holden SK, Sheffler J, Stewart R, et al. Feasibility of home-based neurologic music therapy for behavioral and psychological symptoms of dementia: a Pilot Study. J Music Ther. 2019;56(3):265-286. doi:10.1093/jmt/thz009

45. Schulkind MD. Is memory for music special? Ann N Y Acad Sci. 2009;1169(1):216-224. doi:10.1111/j.1749-6632.2009.04546.x

46. La Joie R, Perrotin A, Barré L, et al. Region-specific hierarchy between atrophy, hypometabolism, and $\beta$-amyloid (A $\beta$ ) load in alzheimer's disease dementia. $J$ Neurosci. 2012;32(46):16265LP16273. doi:10.1523/JNEUROSCI.2170-12.2012 


\section{Publish your work in this journal}

The Journal of Multidisciplinary Healthcare is an international, peerreviewed open-access journal that aims to represent and publish research in healthcare areas delivered by practitioners of different disciplines. This includes studies and reviews conducted by multidisciplinary teams as well as research which evaluates the results or conduct of such teams or healthcare processes in general. The journal covers a very wide range of areas and welcomes submissions from practitioners at all levels, from all over the world. The manuscript management system is completely online and includes a very quick and fair peer-review system. Visit http://www.dovepress.com/testimonials. php to read real quotes from published authors. 